\title{
TINGKAT KEPUASAN PASIEN TERHADAP PELAYANAN KEFARMASIAN DI PUSKESMAS DOI-DOI KECAMATAN PUJANANTING KABUPATEN BARRU
}

\author{
Hendra Stevani*), Ayu Nabila Putri**), Syarifuddin Side ${ }^{* *}$ \\ *)Jurusan Farmasi Politeknik Kesehatan Makassar \\ ${ }^{* *}$ Prodi DIII Farmasi, YAMASI
}

\begin{abstract}
ABSTRAK
Puskesmas adalah unit pelaksana teknik dinas kesehatan kabupaten/kota yang bertanggung jawab menyelenggarakan pembangunan kesehatan dikecamatan, Penelitian ini bertujuan untuk memperoleh informasi tentang tingkat kepuasan pasien terhadap pelayanan kefarmasian di puskesmas Doi-Doi Kecamatan Pujananting Kabupaten Barru pada tahun 2016, sebagai masukan bagi pihak puskesmas sehingga dapat meningkatkan mutu pelayanan kepada pasien rawat jalan maupun rawat inap di puskesmas. Penelitian ini dilakukan pada bulan Mei - Juni. Jenis penelitian ini adalah penelitian deskriftif dengan menggunakan instrument penelitian berupa kusioner yang ditujukan kepada 47 responden yang sudah minimal 2 (dua) kali datang mengambil obat. Data diolah menggunakan skala likert dan hasil penelitian menunjukkan bahwa tingkat kepuasan pasien terhadap pelayanan kefarmasian di puskesmas Doi-Doi Kecamatan Pujananting Kabupaten Barru pada tahun 2016 dalam kategori puas $(69,93 \%)$.
\end{abstract}

\section{Kata Kunci : Kepuasan, Pelayanan kefarmasian, Puskesmas Doi-Doi Kab.Barrru}

\section{PENDAHULUAN}

Puskesmas merupakan suatu kesatuan organisasi kesehatan fungsional yang merupakan pusat kesehatan masyarakat yang juga membina peran serta masyarakat disamping memberikan pelayanan secara menyeluruh dan terpadu kepada masyarakat diwilayah kerjanya dalam bentuk kegiatan pokok (Adiasmito,2010).

Puskesmas adalah unit pelaksana teknik dinas kesehatan kabupaten/kota yang bertanggung jawab menyelenggarakan pembangunan kesehatan dikecamatan (Gde, 2004).

Pelayanan kefarmasian di puskesmas merupakan satu kesatuan yang tidak terpisahkan dari pelaksanaan upaya kesehatan, yang berperan penting dalam meningkatkan mutu pelayanan kesehatan bagi masyarakat.Pelayanan kefarmasian di puskesmas harus mendukung tiga fungsi pokok puskesmas yaitu sebagai pusat penggerak pembangunan berwawasan kesehatan, pusat pemberdayaan masyarakat, dan pusat pelayanan kesehatan strata pertama yang meliputi pelayanan kesehatan perorangan dan pelayanan kesehatan masyarakat.

Memahami kebutuhan dan keinginan konsumen dalam hal ini pasien adalah hal penting yang mempengaruhi kepuasan pasien. Pasien yang puas merupakan aset yang sangat berharga karena apabila pasien puas mereka akan terus melakukan pemakaian terhadap jasa pilihannya. Untuk menciptakan kepuasan pasien puskesmas harus menciptakan dan mengolah suatu sistem untuk memperoleh pasien yang lebih banyak dan kemampuan untuk mempertahankan pasiennya.

Standar kepuasan pasien terhadap pelayanan kefarmasian di puskesmas meliputi pengelolaan obat dan bahan medis habis pakai serta pelayanan farmasi klinis. Pelayanan farmasi klinis meliputi pengkajian resep, penyerahan dan pemberian informasi obat, pelayanan informasi obat (PIO), konseling, ronde/visite pasien pada puskesmas rawat inap, pemantauan dan pelaporan efek samping obat.

Upaya yang perlu dilakukan untuk mewujudkan pelayanan farmasi sesuai standar 
yang dilakukan semaksimal mungkin dengan senantiasa mengedepankan tanggung jawab profesi (pharmaceutical care) dalam upaya peningkatan kualitas hidup pasien hal penting yang harus dilakukan adalah dengan membangun pelayanan kefarmasian yang lebih baik dan dapat dirasakan oleh masyarakat secara umum, karena kualitas layanan adalah hak mutlak yang harus diperoleh oleh masyarakat Indonesia tidak pandang bulu.

Dari uraian di atas dapat dirumuskan masalah, yaitu sejauh mana tingkat kepuasan pasien terhadap pelayanan kefarmasian di puskesmas Doi-Doi Kecamatan Pujananting Kabupaten Barru?

Penelitian ini bertujuan untuk memperoleh informasi tentang tingkat kepuasan pasien terhadap pelayanan kefarmasian di puskesmas Doi-Doi Kecamatan Pujananting Kabupaten Barru pada tahun 2016.

\section{METODE DAN BAHAN \\ Jenis Penelitian}

Jenis penelitian ini adalah penelitian deskriptif dengan menggunakan koesioner sebagai instrument pengumpulan data.

\section{Waktu dan Tempat Penelitian}

Penelitian ini dilaksanakan pada bulan Mei - Juni 2016, data di ambil di Puskesmas Doi-Doi Kecamatan Pujananting Kabupaten Barru.

\section{Populasi dan sampel}

Populasi dari penelitian ini adalah masyarakat yang datang berobat di puskesmas Doi-doi sejumlah \pm 101 orang perbulan. Sampel dipilih berdasarkan pertimbangan tertentu, seperti pasien yang berusia :

a. 17 tahun ke atas

b. minimal dua kali datang berobat

c. bersedia mengisi kusioner.

d. dapat berkomunikasi.

\section{Teknik Pengumpulan Data}

a. Pengumpulan data dilakukan dengan menyebarkan angket (kuesioner). b. Kuesioner dibuat berdasarkan kuesioner komunitas farmasi NHS (National Health Service)

\section{Pengolahan data dan analisa data}

Data yang diperoleh ditabulasi dalam bentuk skor, dihitung total skor untuk pertanyaan dari setiap subvariabel lalu dipersentasekan. Scoring untuk setiap jawaban dari kuesioner di olah berdasarkan skala liker

Skor untuk jawaban sangat puas $=4$

Skor untuk jawaban puas $\quad=3$

Skor untuk jawaban kurang puas $=2$

Skor untuk jawaban tidak puas $\quad=1$

Presentase skor $=\frac{\text { jumlah } \text { skor } \text { rata }- \text { rata }}{\text { skor } \text { ideal }} \times 100 \%$

Skor rata-rata $=\frac{\text { nilai skor responden }}{\text { jumlah butir soal }}$

Skor ideal $=$ jumlah responden $\times 4$

Data yang diperoleh dengan memberikan penilaian terhadap setiap jawaban responden pada kuesioner kemudian dibagi dalam kategori yaitu:

1. Sangat puas $: 75 \%-100 \%$

2. Puas : :50\%-74\%

3. Kurang puas $: 25 \%-49 \%$

4. Tidak puas $: 1 \%-24 \%$

\section{Definisi operasional}

a. Tingkat kepuasan adalah tingkat perasaan pasien yang timbul sebagai akibat dari kinerja layanan kefarmasian di Puskesmas Doi-DoiKecamatan Pujananting Kabupaten Barru

b. Pelayanan kefarmasian adalah suatu pelayanan langsung dan bertanggung jawab kepada pasien yang berkaitan dengan sediaan farmasi dengan maksud mencapai hasil yang pasti untuk meningkatkan mutu kehidupan pasien. Pelayanan kefarmasian di puskesmas seperti pengelola sumber daya yaitu SDM, sarana dan prasarana, sediaan farmasi dan perbekalan kesehatan lainnya serta administrasinya.

c. Puskesmas adalah salah satu organisasi pelayanan kesehatan yang pada dasarnya 
adalah organisasi jasa pelayanan umum. Dalam penelitian ini yang akan dijadikan tempat penelitian adalah Puskesmas DoiDoi Kecamatan Pujananting Kabupaten Barru.

\section{HASIL DAN PEMBAHASAN \\ Hasil Penelitian}

Penelitian ini dilaksanakan di Puskesmas Doi-Doi Kecamatan Pujananting Kabupaten Barru pada bulan Mei - Juni 2016. Data yang diperoleh dengan menggunakan daftar pertanyaan yang telah disusun dalam bentuk kusioner dan dibagikan kepada responden yang telah memenuhi persyaratan yaitu umur 17 tahun ke atas, minimal menebus obat sebanyak 2 (dua) kali, bersedian mengisi kusioner, dapat berkomunikasi.

Selanjutnya hasil penelitian secara lengkap akan di sajikan dalam bentuk tablel yang meliputi karakteristik responden.

a. Berdasarkan jenis kelamin responden Tabel 1. Jenis Kelamin

\begin{tabular}{cc}
\hline Jenis kelamin & N \\
\hline Perempuan & 32 \\
Laki-laki & 15 \\
\hline Jumlah & 47 \\
\hline
\end{tabular}

Sumber : Data Primer 2014

tentang distribusi responden berdasarkan jenis kelamin di Puskesmas DoiDoi Kecamatan Pujananting Kabupaten Barru, dari 47 responden, menunjukan bahwa jenis kelamin responden yang paling banyak adalah perempuan sebanyak 32 orang, sedangkan yang berjenis kelamin laki-laki paling banyak 15 orang.

b. Berdasarkan jenis pertanyaan

Tabel 2 : Mengunjungi Apotek hari ini

\begin{tabular}{lc}
\multicolumn{1}{c}{ PILIHAN } & N \\
\hline Untuk diri sendiri & 47 \\
Orang lain & 0 \\
Keduanya & 0 \\
\hline \multicolumn{1}{c}{ Jumlah } & $\mathbf{4 7}$ \\
\hline
\end{tabular}

Dari tabel diatas menunjukkan bahwa pasien yang datang menebus obat di puskesmas Doi-Doi Kecamatan Pujananting Kabupaten Barru lebih banyak untuk diri sendiri sebanyak 47 orang, untuk orang lain 0 , dan untuk keduanya 0 .

Tabel 3 : Jika Anda Menebus Resep hari ini, Apakah Anda langsung dilayani

\begin{tabular}{lc}
\hline \multicolumn{1}{c}{ PILIHAN } & N \\
\hline Langsung & 38 \\
Menunggu di apotek & 9 \\
Datang kembali nanti & 0 \\
\hline Jumlah & $\mathbf{4 7}$ \\
\hline
\end{tabular}

Dari tabel diatas menunjukkan ketika pasien datang menebus obat untuk penanganan secara langsung 38 orang, yang menjawab menunggu di apotek 9 orang, yang menjawab datang kembali nanti 0 .

Tabel 3: Waktu yang anda butuhkan untuk menebus resep

\begin{tabular}{ccccc}
\hline \multicolumn{5}{c}{ Jumlah responden (orang) } \\
\hline $\begin{array}{c}\text { Sangat } \\
\text { puas }\end{array}$ & Puas & $\begin{array}{c}\text { Kurang } \\
\text { puas }\end{array}$ & $\begin{array}{c}\text { Tidak } \\
\text { puas }\end{array}$ & Jumlah \\
\hline 7 & 26 & 6 & 8 & 47 \\
\hline
\end{tabular}

Dari data diatas Seberapa puas Anda dengan waktu yang dibutuhkan untuk menebus resep atau mendapatkan pelayanan apotek lain yang diperlukan termasuk kategori puas dengan jumlah 26 orang, yang menjawab sangat puas 7 orang, yang menjawab puas 26 orang, yang menjawab kurang puas 6 orang yang menjawab tidak puas 8 orang. 
Tabel 4 :Perbandingan kunjungan anda yang sebelumnya dan kunjungan hari ini, bagaimana Anda menilai apotek pada faktor-faktor berikut ini

\begin{tabular}{|c|c|c|c|c|c|}
\hline \multirow[t]{2}{*}{ Soal } & $\begin{array}{c}\text { Sangat } \\
\text { puas }\end{array}$ & Puas & $\begin{array}{c}\text { Kurang } \\
\text { puas }\end{array}$ & $\begin{array}{l}\text { Tidak } \\
\text { puas }\end{array}$ & jumlah \\
\hline & Orang & Orang & Orang & Orang & orang \\
\hline a. Kebersihan & 6 & 27 & 9 & 5 & 47 \\
\hline b. Kenyamanan & 6 & 27 & 9 & 5 & 47 \\
\hline c. Ketersediaan obat & 6 & 27 & 9 & 5 & 47 \\
\hline d. Tata letak obat yg jelas & 6 & 27 & 9 & 5 & 47 \\
\hline $\begin{array}{l}\text { e. Waktu menunggu } \\
\text { untuk di layani }\end{array}$ & 6 & 27 & 9 & 5 & 47 \\
\hline $\begin{array}{l}\text { f. Tempat yang tersedia } \\
\text { untuk konsultasi }\end{array}$ & 6 & 27 & 9 & 5 & 47 \\
\hline Jumlah & 36 & 162 & 54 & 30 & 282 \\
\hline
\end{tabular}

Sumber: data primer 2016

Dari tabel diatas pasien dapat membandingkan dengan kunjungan sebelumnya dan kunjungan hari ini, bagaimana Anda menilai apotek pada faktor-faktor berikut ini termasuk dalam kategori puas dengan jumlah 162, yang menjawab sangat puas 36 yang menjawab puas 162 yang menjawab kurang puas 54 yang menjawab tidak puas 30 .

Tabel 5 : Bagaimana Anda menilai apoteker dan staf lain yang bekerja di Puskesmas

\begin{tabular}{lccccc}
\hline \multicolumn{1}{c}{ Soal } & $\begin{array}{c}\text { Sangat } \\
\text { puas }\end{array}$ & Puas & $\begin{array}{c}\text { Kurang } \\
\text { puas }\end{array}$ & $\begin{array}{c}\text { Tidak } \\
\text { puas }\end{array}$ & jumlah \\
\cline { 2 - 6 } & Orang & Orang & Orang & Orang & Orang \\
\hline a. Sopan & 9 & 28 & 6 & 4 & 47 \\
b. layanan dari apoteker & 9 & 28 & 6 & 4 & 47 \\
c. layanan dari petugas & 9 & 28 & 6 & 4 & 47 \\
$\quad \begin{array}{l}\text { lain } \\
\text { d. pelayanan efisien }\end{array}$ & 9 & 28 & 6 & 4 & 47 \\
e. layanan dri staf & & 28 & 6 & 4 & 47 \\
\hline \multicolumn{1}{c}{ keseluruhan } & 9 & $\mathbf{1 4 0}$ & $\mathbf{3 0}$ & $\mathbf{2 0}$ & $\mathbf{2 3 5}$ \\
\hline
\end{tabular}

Sumber: data primer 2016

Dari tabel diatas pasien membandingkan dengan kunjungan sebelumnya dan kunjungan hari ini, bagaimana Anda menilai apoteker dan staf lain yang bekerja di sana berikut ini termasuk kategori puas dengan jumlah 140, yang menjawab sangat puas 45, yang menjawab puas 140 , yang menjawab kurang puas 30 , yang menjawab tidak puas 20 .
Tabel 6 : Penilaian anda terhadap Staff, apotek dan layanan yang disediakan

\begin{tabular}{ccccc}
\hline $\begin{array}{c}\text { Sangat } \\
\text { puas }\end{array}$ & $\begin{array}{c}\text { Puas } \\
\text { Orang }\end{array}$ & $\begin{array}{c}\text { Kuran } \\
\text { g puas }\end{array}$ & $\begin{array}{c}\text { Tidak } \\
\text { puas }\end{array}$ & jumlah \\
\hline 8 & 34 & 5 & 0 & 47 \\
\hline
\end{tabular}

Sumber: data primer 2016

Dari data diatas bagaimana penilaian anda terhadap Staff, apotek dan layanan yang disediakan yang termasuk kategori puas berjumlah 104 yang menjawab sangat puas 32, 
yang menjawab puas 104, yang menjawab kurang puas 24, yang menjawab tidak puas 28 .

Tabel 7 : Apakah anda mendapatkan saran dari staf pelayanan

\begin{tabular}{lcc}
\multicolumn{1}{c}{ Soal } & Ya & tidak \\
\hline Berhenti & 19 & 28 \\
merokok & 30 & 7 \\
Makan sehat & 33 & 14 \\
Latihan fisik & $\mathbf{8 2}$ & $\mathbf{4 9}$
\end{tabular}

Sumber: data primer 2016
Dari data diatas yang mendapat saran tentang salah satu hal berikut dari apoteker atau staf yang mendapatkan saran berhenti merokok sebanyak 19 orang dan yg tidak mendapat saran berhenti merokok sebanyak 28 orang, yang mendapatkan saran untuk makan sehat sebanyak 30 orang dan yang tidak mendapatkan saran untuk makan sehat sebanyak 7 orang, yang mendapatkan saran untuk latihan fisik sebanyak 33 orang dan yang tidak mendapatkan saran latihan fisik sebanyak 14 orang.

Tabel 8: Seberapa baik layananan yang diberikan kepada Anda?

\begin{tabular}{cccccc}
\hline Soal & $\begin{array}{c}\text { Sangat } \\
\text { puas }\end{array}$ & Puas & $\begin{array}{c}\text { Kurang } \\
\text { puas }\end{array}$ & $\begin{array}{c}\text { Tidak } \\
\text { puas }\end{array}$ & Jumlah \\
\cline { 2 - 6 } & Orang & Orang & Orang & Orang & Orang \\
\hline $\begin{array}{c}\text { a. saran pada masalah } \\
\text { kesehatan }\end{array}$ & 8 & 26 & 6 & 7 & 47 \\
$\begin{array}{c}\text { b.saran untuk gaya } \\
\text { hidup }\end{array}$ & 8 & 26 & 6 & 7 & 47 \\
$\begin{array}{c}\text { c. membuang obat saat } \\
\text { tidak dibutuhkan }\end{array}$ & 8 & 26 & 6 & 7 & 47 \\
$\begin{array}{c}\text { d.memberikan saran } \\
\text { dan informasi yang } \\
\text { dibutuhkan }\end{array}$ & 8 & 26 & 6 & 7 & 47 \\
\hline Jumlah & $\mathbf{3 2}$ & $\mathbf{1 0 4}$ & $\mathbf{2 4}$ & $\mathbf{2 8}$ & $\mathbf{1 8 8}$ \\
\hline
\end{tabular}

Data: sumber primer 2016 


\section{Pembahasan}

Hasil penelitian yg diperoleh di Puskesmas Doi-Doi kecamatan pujananting kabupaten barru diperoleh bahwa pasien merasa puas dengan pelayanan yg di berikan oleh staf pelayanan yang ada di puskesmas.

Mengapa anda mengunjungi apotek hari ini, banyaknya pasien yang datang untuk menebus obat untuk diri sendiri seanyak 47 orang, yang datang untuk orang lain 0 , untuk keduanya 0 . Di karenakan pasien lebih memilih untuk datang sendiri menebus obat.

Jika anda menebus resep hari ini, apakah anda langsung dilayani , apakah harus menunggu di apotek atau harus kembali nanti untuk mengambil obat, langsung 38 orang, menunggu di apotek 9 orang, datang kembali nanti 0 orang, staf pelayanan mengutamakan untuk melayani pasien secara langsung karna masih minimnya orang yg datang berobat perharinya.

Seberapa puas anda dengan waktu yang dibutuhkan untuk menebus resep atau mendapatkan pelayanan apotek lain yang diperlukan, dari hasil diatas dapat diketahui bahwa pasien termasuk dalam kategori puas 26 orang, hal ini dapat dilihat dari jawaban 47 Responden yang menjawab sangat puas (7 orang), puas (26 orang), kurang puas (6 orang), tidak puas (8 orang).

Pasien dapat membandingkan dengan kunjungan sebelumnya dan kunjungan hari ini, bagaimana Anda menilai apotek pada faktor-faktor berikut ini dari hasil presentase dapat diketahui bahwa pasien termasuk dalam kategori puas 27 orang, hal ini dapat dilihat dari jawaban 47 Responden yang menjawab sangat puas (6 orang), puas (27 orang), kurang puas (9 orang), tidak puas (5 orang).

Bandingkan dengan kunjungan sebelumnya dan kunjungan hari ini, bagaimana Anda menilai apoteker dan staf lain yang bekerja di sana, berikut ini dari hasil presentase dapat diketahui bahwa pasien termasuk dalam kategori puas 28 orang hal ini dapat dilihat dari jawaban 47 Responden yang menjawab sangat puas (9 orang), puas (28 orang), kurang puas (6 orang), tidak puas (4 orang).

Terhadap semua waktu yang anda gunakan di Apotek ini, seberapa baik layananan yang diberikan kepada Anda, dapat diketahui bahwa hasil jawaban termasuk kategori puas 26 orang, hal ini dapat dilihat dari jawaban 47 responden yang menjawab sangat puas (8 orang), puas (26 orang), kurang puas (6 orang), tidak puas (7 orang).

Apakah anda mendapatkan saran tentang salah satu hal berikut dari apoteker atau staf, saran untuk pasie berhenti merokok sebanyak 19 orang dan yang tidak sebanyak 28 orang, yang mendapat saran makan makanan sehat sebanyak 30 orang dan yang tidak sebanyak 7 orang, yg mendapat saran untuk latihan fisik sebanyak 33 orang dan yang tidak sebanyak 14 orang.

Penilain seorang pasien terhadap staf apotek dan layanan yang disediakan, dari hasil yang di dapat dari jawaban responden termasuk kategori puas 34 orang, dimana sebagian besar pasien menjawab sangat puas ( 8 orang), puas (34 orang), namun masih terdapat pasien yang menjawab kurang puas (5 orang), karena pasien dapat menilai seorang staf atau pelayanan kesehatan lainnya dari sikap dan kesopanan saat staf kesehatan melayani soerang pasien.

Kepuasan pasien adalah suatu tingkat perasaan pasien yang timbul sebagai akibat dari kinerja layanan kesehatan yang diperolehnya setelah pasien membandingkan dengan apa yang diharapkanya.

Berdasarkan hasil penelitian yang diperoleh dapat disimpulkan bahwa tingkat kepuasan pasien terhadap pelayanan kefarmasian di Puskesmas Doi-Doi Kecamatan Pujananting Kabupaten Barru termasuk dalam kategori puas sebesar $69,93 \%$

Dari keseluruhan hasil penelitian diperoleh presentase jawaban responden sebesar 69,93\% Berarti tingkat kepuasan pasien terhadap pelayanan kefarmasian termasuk dalam kategori puas.

\section{PENUTUP \\ Kesimpulan}

Berdasarkan hasil penelitian yang diperoleh dapat disimpulkan bahwa tingkat kepuasan pasien terhadap pelayanan kefarmasian di Puskesmas Doi-Doi Kecamatan Pujananting Kabupaten Barru termasuk dalam kategori puas dengan 
presentase jawaban responden sebesar $69,93 \%$.

\section{Saran}

1. Perlu ditingkatkan rasa kepuasan pasien terhadap pelayanan kefarmasian.

2. Sebaiknya petugas farmasi memberikan informasi obat yang lebih jelas kepada pasien agar tidak terjadi kesalahan saat meminum obat contohnya penggunaan antibiotic yang harus dihabiskan, agar pasien dapat meminum obat secara teratur

3. Keramahan petugas farmasi harus lebih diperhatikan sebab hal ini juga termasuk pandangan pasien yang sangat penting yang dapat menimbulkan sikap pasien agar pasien senang berobat di puskesmas dan mau datang berobat kembali.

\section{DAFTAR PUSTAKA}

A.A. Gde Muninjaya. (2004). Manajemen Kesehatan. Jakarta: Penerbit BukuKedokteran EGC: 220234.Persada http://eprint.ung.ac.id/id/eprint/481 $\underline{1 \text { (di akses tanggal12 februari } 2016}$

Adisasminto, Wiku. (2010). Sistem Kesehatan. Jakarta: PT Raja Grafindo Persadah http://eprint.ung.ac.id/id/eprint/481 1 (di akses tanggal12 februari 2016

Amir , A. 2015. Studi tingkat kepuasan pasien terhadap Pelayanan Kefarmasian di Puskesmas Watampone Kota Bone . Akademi Farmasi Yamasi, Makassar.

Anonim. (2006). Ketersediaan HayatiObat.ht tp//www.Psortalkalbe.com (Tanggal Akses Juli 2008.)

Http://upelkes-kalbar.com/peran-tenagafarmasi-dalam-akreditasi-dipuskesmas/(di akses tanggal 20 $\underline{\text { maret) }}$

Pohan, I.S. (2007). Jaminan mutu Layanan Kesehatan : Dasar-dasar Pengertian dan Penerapan. Jakarta. EGC.Siregar, Charles. JP., 2004. Farmasi Rumah Sakit Teori dan Penerapan. Cetakan I, Penerbit EGC, Jakarta 